\title{
ON SEROUS EFFUSION
}

FROM THE

\section{MEMBRANES}

AND INTO THE

\section{VEŃTRICLES OF THE BRAIN, AXP}

ITS CONNECTION WITH APOPLEXY

AND OTHER

DISEASES OF THE BRAIN.

By JOHN SIMS, M.D.,

PHYSICIAN TO THE ST. MARY-LE-BONE INFIRMARY.

READ APRIL 28TH, 1835.

ON dissecting the bodies of persons who have died of apoplexy, three morbid states of the brain have been more particularly noticed :-an unusually loaded state of the blood-vessels, - extravasation of blood, -effusion of serous fluid from the membranes or into the ventricles.

Several other appearances are met with, as tumours of various kinds, diseased blood-vessels, cysts containing fluids, a hard or a softened state of the brain, to which may be added hypertrophy and atrophy of the brain. Many fatal apoplectic cases are related by authors in which no change of structure in the brain, or deposit of any kind, has been noticed: the brain has in these instances appeared perfectly healthy. 
Systematic authors have divided apoplexy into two species-the sanguineous and serous; and have attempted to define the peculiar and characteristic symptoms of both, and their appropriate or even opposite treatment. On the other hand, practical writers have doubted the reported frequency of serous apoplexy, or denied its existence altogether. Many cases have fallen under my observation, which appear to me to illustrate and confirm the latter opinion, and in the following paper I shall adduce numerous facts and arguments in support of this view of the subject.

Several of the older anatomists are well known to have paid considerable attention to the subject of serous effusion within the cranium, but to quote the various opinions and suppositions of medical writers on this important affection, would unnecessarily extend my communication beyond its proper limits. I shall, however, briefly advert to the views taken of it by some of the more modern British authors.

Dr. Heberden observes :-_ “ Books do indeed make a distinction between a pituitous and sanguineous apoplexy, in the latter only of which they recommend bleeding: but this difference is not easy to be seen, and seems hardly ever looked for in practice."*

Dr. Cheyne, in his chapter on serous apoplexy,

* Medical Transactions of College of Physieians. Vol. I. p. 473. 
after alluding to the contradictory opinions of preceding authors respecting the existence, the nature, and the treatment of this affection, states :- " I cannot hope to reconcile these opinions, after the unsuccessful efforts which have been made by physicians respected by the whole profession; the attempt would be presumptuous; I shall therefore steer a safe course, and content myself with a simple relation of my experience." He alludes to five instances wherein he had been called upon to explain the cause of death in persons who had died in the course of the night, and were found with pale and placid countenances. One of these only he examined. He then mentions,"A sixth patient $I$ attended during an illness which lasted forty hours; and I very carefully watched the dissection. The case of this patient is a specimen of serous apoplexy, and is, I believe, the only one I ever attended." The dissection of the patient is said to resemble exactly that of one of the five bodies which he examined. I would submit that this case is more strictly referable to acute inflammation of the substance of the brain, from the history of the symptoms, and from the description of the morbid:appearances. Dr. C. notes that " on the pia mater there prevailed signs of inflammation." "The sub. stance of the brain was unusually soft." And further, from the following remark, - "In all Morgagni’s dissections, under the head of serous apoplexy, there appeared venous turgescence, and effusion of serum; and in the dissection of serous apoplexy which I directed, although the veins were not very turgid, 
there was evidence of increased arterial action having existed shortly before death.”*

In the thirty-seven dissections of maniacs related by Dr. Haslam in his work on madness, there are several cases and remarks which illustrate the nature of serous effusion in the brain $\uparrow$.

Crowther instances a case of a furious madman, in which various signs of altered structure were present, and a greater accumulation of water than he had ever

* Cheyne on Apoplexy.-The author gives the following summary of his observations on the morbid anatomy of apoplexy.

"I have now related all the morbid appearances which I have witnessed in my dissections after apoplexy; but such a detail seldom leads to the knowledge of that peculiar condition of the organ upon which the disease may be said to depend; I shall therefore add a summary of the most important of these appearances, in what I conceive the order of their importance.

"I mention first, the remains of an excited state of the minute arteries of the brain and its membranes, this probably being the most important, as it is the most unvarying appearance; then the extravasation of blood, probably the consequence of the excited state of the blood vessels; the turgescence of the venous system; the enlargement of the ventricles, partial or general; and lastly, the serous effusion which is generally found in various parts of the brain, and which would seem to imply previous absorption of the brain."-Cases of Apoplexy and Lethargy, 1812.

+ Case 30. "A man, æt. 55: the last fortnight only his mind became violently agitated : -8 oz. fluid were taken from the ventricles.

"As the patient remained in the hospital from the middle of January to the beginning of May, in a state perfectly tranquil, and without the appearance of disarrangement of mind, it is improbable that a so great enlargement of the ventricles, and accu- 
seen before, yet the patient had a lucid interval before death, and had no "symptoms of the hydrocephalic kind"*.

In some of the cases of chronic hydrocephalus related by Dr. Mills, it appears highly probable that the fluid had been collected for some time, and that the symptoms were not produced by its presence within the cranium $\uparrow$.

Dr. Cooke, in his learned history of nervous diseases, in the chapter treating of the dissections of cases of apoplexy, after reviewing the opinions of preceding writers, concludes :- " On the whole, if we admit the distinction of apoplexy into the sanguineous and serous, I think we must also admit that the serous apoplexy very seldom occurs."

Dr. Bright and Dr. Abercrombie, two of the best practical authorities in this country, have devoted considerable attention to the illustration of this and other forms of cerebral disease. Dr. Bright observes : "When from any cause the balance of circulation is

mulation of water, could have taken place within the short space of two weeks; it is therefore most likely that the greatest part of this fluid had been previously collected."-Observations on Madness, \&c. 1809.

* Remarks on Insanity. p. 26.

+ On the Pathology of Hydrocephalus, in Trans. of Dublin College of Physicians. Vol. I. p. 352.

$\ddagger$ On Nervous Disorders. Vol. I. p. 268. 
destroyed, serous effusion is very apt to take place; and from the unyielding nature of the parietes, any unusual accumulation of fluid very quickly produces manifest effects ; and a much smaller quantity of serum, if rapidly effused, will destroy life in the brain, than if in comneetion with any other organ or cavity. The causes which produce serous effusion are, no doubt, the same in the brain as in other parts; but, from the circumstances I have just mentioned, they are more easily called into action, and more injurious when they exist."*

At the conclusion of the section entitled "Of the Cases primarily Apoplectic," including " Simple Apoplexy and Apoplexy with Serous Effusion," in Dr. Abercrombie's work on the Brain, the author infers," 1 st, That there is a modification of apoplexy, which is fatal, without leaving any morbid appearance that can be discovered in the brain. 2dly, There is another modification in which we find serous effusion, often in small quantity." " 4 thly, Without any apoplectic symptoms we find serous effusion in the brain in an equal or greater degree than in the cases of the second modification ;" consequently that " in these cases it is probable the effusion is not the cause of the symptoms." Dr. A. states the following as the probable cause of the serous effusion :- " That the serous effusion is to be considered as the result of that peculiar derangement of the circulation which constitutes the state of

" Hospital Reports, " Brain." p. 657. 
simple apoplexy. In other words, it is probable that the affection which has been called serous apoplexy is to be considered as simple apoplexy terminating by effusion." * It is necessary to remark, that Dr. Abercrombie's definition of simple apoplexy is confined exclusively to those cases in which " no morbid appearance whatever can be detected after the most careful examination." His opinion, therefore, rests on the supposition of a peculiar derangement of the circulation in such subjects $t$.

Notwithstanding the preceding evidence, it is still a very prevalent opinion that if a person, rather advanced in life, fall down in a fit, and suddenly expire, or survive but a short time with coma, insensibility, stertorous breathing, \&c., that if the head of such a person be examined, and effusion to any extent be found between the membranes or in the ventricles without any extravasation of blood, that death has: been occasioned by what is termed serous apoplexy. This opinion, which is considered a satisfactory one, is often given to the surviving friends of a patient, and by the medical witnesses examined in cases of inquest before the coroner and other judicial tribunals. I think the following cases and observations will tend to shew that this opinion is very frequently erroneous, and that they will, on the other hand, lead to the

* Researches on the Brain, p. 217.

+ Vide "A Commentary on Apoplectic and Paralytic Affections and on the Diseases connected with the subject," by Thomas Kirkland, M.D. 1792. 
conclusion, that persons dying suddenly or speedily under these circumstances are more likely to have suffered an attack of simple sanguineous apoplexy, or that form of the disease in which a loaded state of the blood-vessels is discovered on dissection. Of course I exclude from consideration all other causes of death in persons who may have suffered a sudden and fatal seizure *.

My object in the present paper is strictly pathological, but the practical bearing resulting from accurate views of this subject is of the first importance."In considering these subjects, it is necessary to discard all preconceived opinions, and to collect simply the inferences from facts." $\uparrow$

I propose to relate the facts and observations con-

* Sir Henry Halford, in a paper read at the College of Physicians, Jan. 26, 1835, “On the Deaths of some eminent Persons of Modern Times," makes the following allusion to the inspection of the brain of the celebrated Dean Swift. "In process of time there ensued that plethoric state of the brain which required frequent cupping; and at length the obstruction became so great as to occasion an effusion of water into the ventricles, and the loss of his faculties by apoplectic pressure. This appeared on examination of the head after death. No doubt this effusion had been preceded by inflammation of the membranes of the brain, and by phrenzy." Med. Gaz. Vol. XV. p. 634.

I trust a consideration of the facts and arguments contained in this paper will afford a different explanation respecting the fluid in the brain.

+ Dr. Prichard on Nervous Diseases. 
nected with this form of disease under the following heads :-

I. Serous effusion in the brain, or its membranes, of persons dying of various diseases not cerebral, and who had manifested no symptoms referable to the brain.

I1. Serous effusion into the ventricles or membranes, to a considerable extent, in cases where old apoplectic cysts were found, with or without attendant paralysis : the patients being destroyed by diseases not cerebral.

III. Serous effusion into the ventricles or membranes of unquestionably long standing, with old apoplectic cysts : the patients being destroyed by recent extravasation of blood within the cranium.

\section{Cases of simple sanguineous apoplexy.}

V. Cases of serous effusion into the membranes or ventricles of old standing, with loaded, dilated, or diseased blood-vessels, frequently denominated serous apoplexy, but more properly referable to simple sanguineous apoplexy. 
I.

"Serous effusion in the brain or its membranes in persons dying of various diseases not cerebral, and who manifested no symptoms referable to the brain."

The very great frequency of collections of serous fluid found in the ventricles or membranes of the brain, in cases where no cerebral symptoms were known to have existed, is a subject of great importance to pathologists and practical physicians, especially when viewed in reference to the discrimination and curative treatment of apoplexy and other diseases of the nervous system. There is also a great variety of other morbid appearances found on dissection of the brain, in cases where no symptoms, or no symptoms adequate to explain the phenomena, were noticed during life.

With the view of attempting to illustrate this subject, I have put together, in a tabular form, a number of dissections of persons who were destroyed by various forms of disease in the thorax and abdomen, in whom what are generally considered morbid alterations were also discovered in the brain or its membranes.

From this Table, which is taken from a great variety of cases of all ages and various diseases, I have excluded all those in which coma, convulsions, or any other known sign of cerebral disease occurred during life. 


\section{Table I.}

Containing fifty cases of persons who died of various diseases, not cerebral, and who manifested no symptoms referable to the brain, but on dissection effusion of fluid and other morbid appearances were found in the brain or membranes.

\begin{tabular}{|c|c|c|c|c|c|c|}
\hline \multirow{2}{*}{ No. } & \multirow{2}{*}{ Sex } & \multirow{2}{*}{ Age } & \multirow{2}{*}{$\begin{array}{c}\text { Disease causing } \\
\text { death. }\end{array}$} & \multicolumn{2}{|c|}{ Effusion. } & \multirow{2}{*}{ Other morbid states of the brain. } \\
\hline & & & & Membranes. & Ventricles. & \\
\hline 1. & M. & 66 & $\begin{array}{l}\text { Purpurahæmor- } \\
\text { rhagica. }\end{array}$ & Great quantity. & 3 oz. $\cdot \cdot$ & $\begin{array}{l}\text { Part of the surface of posterior and } \\
\text { middle lobe of right hemisphere }\end{array}$ \\
\hline 2. & M. & 50 & Phthisis pulmo- & Extensive sub- & Much . • • & $\begin{array}{l}\text { fawn coloured. } \\
\text { Two small tubercles in one of the in- }\end{array}$ \\
\hline 3. & F. & 53 & Cholera $\cdot \cdot \cdot$ & $\cdot \cdot \cdot \cdot \cdot \cdot$ & $\cdot \cdot \cdot \cdot \cdot$ & Cranlum loaded with blood. Blood- \\
\hline 4. & F. & 55 & Diseased heart. & $\cdot \cdot \cdot \cdot \cdot$ & 4 oz. . . . & $\begin{array}{l}\text { High congestion of skull, mem- } \\
\text { branes, and brain. Velum inter- }\end{array}$ \\
\hline 5. & M. & 43 & $\begin{array}{l}\text { Fungoid disease } \\
\text { of heart and }\end{array}$ & Great quantity. & $\cdot \cdot \cdot \cdot \cdot$ & $\begin{array}{l}\text { Tunica arachnoidea white and uni- } \\
\text { versally opaque. }\end{array}$ \\
\hline 6. & F. & 35 & $\begin{array}{l}\text { Hypertrophy of } \\
\text { heart. }\end{array}$ & Fluid separating & Small quantity. & \\
\hline 7. & F. & 29 & $\begin{array}{l}\text { Phthisis pulmo- } \\
\text { nalis. }\end{array}$ & Fluid in sub- & Some. & \\
\hline 8. & F. & 11 & Pneumonia . & $\cdot \cdot \cdot \cdot \cdot \cdot$ & Fluid in ventri- & Opacity of arachnoid and velum in- \\
\hline 9. & M. & 4 & $\begin{array}{l}\text { Pleuro - perip- } \\
\text { neumonia. }\end{array}$ & Much in sub- & & \\
\hline 10. & F. & 28 & Puerperal peri- & Some effusion. & Some . . . & Brain bloodless. \\
\hline 11. & F. & 2 & Pneumonia . & Much beneath & $6 \mathrm{oz} . .$. & Fluid remarkably clear. \\
\hline 12. & M. & 74 & Diseased heart. & Great effusion.. & $\cdot \cdot \cdot \cdot \cdot \cdot$ & Blood-vessels congested. Arteries at \\
\hline 13. & M. & 56 & Diseased heart. & Fluid . • • & 4 oz. . . . . & $\begin{array}{l}\text { Hypertrophy of frontal bones. Tu- } \\
\text { nica arachnoidea thick and opaque. } \\
\text { Arteries ossified. }\end{array}$ \\
\hline 14. & M. & 56 & $\begin{array}{l}\text { Phthisis. Fun- } \\
\text { goid disease of } \\
\text { kidney. }\end{array}$ & Effusion . . & Effusion. & \\
\hline 15. & F. & 20 & $\begin{array}{l}\text { Disease of vari- } \\
\text { ous organs. }\end{array}$ & Much fluid . & $\cdot \cdot \cdot \cdot \cdot$ & $\begin{array}{l}\text { Opacity of arachnoid. Distinct plugs } \\
\text { of coagulable lymph in longitudinal } \\
\text { and lateral sinuses. }\end{array}$ \\
\hline 16. & M. & 54 & $\begin{array}{l}\text { Fungus hæmat. } \\
\text { of kidney. }\end{array}$ & $\begin{array}{l}\text { Very great quan- } \\
\text { tity. }\end{array}$ & $\cdot \cdot \cdot \cdot \cdot$ & antity of fluid left in base \\
\hline 17. & F. & 24 & Crural phlebitis. & Effusion on sur- & •. • • • & Brain bloodless. \\
\hline 18. & F. & 22 & $\begin{array}{l}\text { Abscess of liver. } \\
\text { Peritonitis. }\end{array}$ & $\begin{array}{l}\text { Fluid between } \\
\text { membranes. }\end{array}$ & & \\
\hline 19. & M. & 50 & Phthisis pul- & Much fluid . & $\cdot \cdot \cdot \cdot \cdot$ & Great congestion of blood-vessels. \\
\hline 20. & F. & 76 & $\begin{array}{l}\text { Diseased heart. } \\
\text { Hydrothorax. }\end{array}$ & Great effusion. . & $\cdot \cdot \cdot \cdot \cdot$ & $\begin{array}{l}\text { Blood-vessels all turgid. Brain red- } \\
\text { brown, from }\end{array}$ \\
\hline 21. & M. & 75 & $\begin{array}{l}\text { Slough on sa- } \\
\text { crum, great } \\
\text { emaciation. }\end{array}$ & Great quantity. & $\bullet \cdot \bullet \cdot \cdot$ & $\begin{array}{l}\text { Opacity of arachnoid. Brain tough, } \\
\text { fibrous. }\end{array}$ \\
\hline $\begin{array}{l}22 . \\
23 .\end{array}$ & M. & $\begin{array}{l}67 \\
23\end{array}$ & $\begin{array}{l}\text { Diseased heart. } \\
\text { Phthisis pulmo- } \\
\text { nalis. }\end{array}$ & $\begin{array}{l}\text { Effusion } \\
\text { Very great quan- } \\
\text { tity. }\end{array}$ & $\cdot \cdot \cdot \cdot \cdot$ & Opacity of membranes. \\
\hline 24. & M. & 69 & $\begin{array}{l}\text { Phthisis pulmo- } \\
\text { nalis. }\end{array}$ & $\begin{array}{l}\text { Much fluid in } \\
\text { tissue. }\end{array}$ & $\begin{array}{l}\text { And in ventri- } \\
\text { cles. }\end{array}$ & $\begin{array}{l}\text { Membranes opaque and tough. For- } \\
\text { nix softened. Septum l. absorbed. } \\
\text { Basilary artery dilated; tortuous. }\end{array}$ \\
\hline 25. & M. & $\begin{array}{l}84 \\
50\end{array}$ & $\begin{array}{l}\text { Diseased bladder } \\
\text { Ulceration of } \\
\text { intestine. }\end{array}$ & Great quantity. & Great quantity. & $\begin{array}{l}\text { Arachnoid of dura mater very thick } \\
\text { and dusky red colour. Lining } \\
\text { membrane of ventricles granular }\end{array}$ \\
\hline 27. & F. & 22 & $\begin{array}{c}\text { Phthisis } \\
\text { monalis. }\end{array}$ & Fluid • • & $\cdot \cdot \cdot \cdot$ & $\begin{array}{l}\text { and rough. } \\
\text { Opaque membranes. Tubercle on } \\
\text { dura mater size of a pea. }\end{array}$ \\
\hline
\end{tabular}




\begin{tabular}{|c|c|c|c|c|c|c|}
\hline \multirow{2}{*}{ No. } & \multirow{2}{*}{ ex } & \multirow{2}{*}{ Age } & \multirow{2}{*}{$\begin{array}{c}\text { Disease causing } \\
\text { death. }\end{array}$} & \multicolumn{2}{|c|}{ Effusion. } & \multirow[b]{2}{*}{ Other morbid states of the brain. } \\
\hline & & & & Membranes. & Ventricles. & \\
\hline 28. & F. & 58 & Abscess of thigh & Large quantity. & $\cdot \cdot \cdot \cdot \cdot$ & General opacity of arachnoid. \\
\hline 29. & F. & 57 & $\begin{array}{c}\text { Diseased heart. } \\
\text { Ulceration of } \\
\text { intestines. }\end{array}$ & Large quantity. & & \\
\hline 30. & M. & 64 & $\begin{array}{l}\text { Cancer of sto- } \\
\text { mach and liver. }\end{array}$ & Much fluid. & 6 oz. & $\begin{array}{l}\text { Blood-vessels tortuous; congested. } \\
\text { Septum lucidum broken. }\end{array}$ \\
\hline $\begin{array}{l}31 . \\
32 .\end{array}$ & M. & $\begin{array}{l}40 \\
36\end{array}$ & $\begin{array}{l}\text { Phthisis pulmo. } \\
\text { Phthisis pul- } \\
\text { monalis. }\end{array}$ & $: \vdots: \vdots:$ & $\begin{array}{l}\text { Great quantity. } \\
\text { Great quantity. }\end{array}$ & Arachnoid cloudy. \\
\hline 33. & M. & 10 & $\begin{array}{l}\text { Phthisis pul- } \\
\text { monalis. }\end{array}$ & Some . • . & Some $\cdot \cdot \cdot$ & Blood-vessels gorged. Arachnoid \\
\hline 34. & M. & 39 & Phthisis pul- & $\cdot \cdot \cdot \cdot \cdot$ & Large quantity. & Membranes thick and opaque. \\
\hline 35. & M. & 60 & Phthisis pul- & $\cdot \cdot \cdot \cdot \cdot$ & Great quantity. & Opacity of arachnoid. \\
\hline $\begin{array}{l}36 . \\
37 .\end{array}$ & $\begin{array}{l}\text { M. } \\
\text { F. }\end{array}$ & $\begin{array}{r}8 \\
25\end{array}$ & $\begin{array}{l}\text { Diseased joints. } \\
\text { Phthisis pul- } \\
\text { monalis. }\end{array}$ & $\begin{array}{l}\text { Great quantity. } \\
\text { Very great quan- } \\
\text { tity. }\end{array}$ & $\begin{array}{ll}2 \text { oz. } \\
4 \mathrm{oz} .\end{array}$ & lopaque. \\
\hline 38. & F. & 80 & Phthisis pul- & Large quantity. & $4 \mathrm{oz}$ & \\
\hline 39. & F. & 66 & $\begin{array}{l}\text { Cancer of sto- } \\
\text { mach. }\end{array}$ & Large quantity. & $\cdot \cdot \cdot \cdot \cdot$ & Blood-vessels gorged. \\
\hline 40. & M. & 63 & $\begin{array}{l}\text { Inflammation of } \\
\text { pleura, peri- } \\
\text { toneum, \&c. }\end{array}$ & $\cdot \cdot \cdot \cdot \cdot$ & $\cdot \cdot \cdot \cdot \cdot$ & $\begin{array}{l}\text { Blood-vessels gorged. Great milki- } \\
\text { ness and thickening of arachnoid. }\end{array}$ \\
\hline 41. & F. & 69 & Cancer of liver. & $\cdot \cdot \cdot \cdot \cdot$ & $\cdot \cdot \cdot \cdot \cdot$ & $\begin{array}{l}\text { Falsemembrane in the cavityof arach- } \\
\text { noid. Dense deposit along longitu- } \\
\text { dinal sinus: }\end{array}$ \\
\hline 42. & M. & $\begin{array}{l}47 \\
64\end{array}$ & $\begin{array}{l}\text { Diseased liver. } \\
\text { Seirrhous rec- } \\
\text { tum. }\end{array}$ & 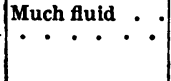 & $\therefore: \vdots: \dot{:}$ & $\begin{array}{l}\text { Thickening of membranes. } \\
\text { Fibrous tumour size of an almond, } \\
\text { resting on left anterior clynoid } \\
\text { process. }\end{array}$ \\
\hline 44. & F. & 49 & $\begin{array}{c}\text { Scirrhous pylo- } \\
\text { rus. }\end{array}$ & $\cdot \cdot \cdot \cdot \cdot$ & $\cdot \cdot \cdot \cdot \cdot$ & $\begin{array}{l}\text { Recent arachnitis. Layer of lymph. } \\
\text { Thick deposit along longitudinal }\end{array}$ \\
\hline 45. & M. & 60 & $\begin{array}{l}\text { Phthisis. Ulcer- } \\
\text { ation of intest. }\end{array}$ & $\begin{array}{l}\text { Very great quan- } \\
\text { tity. }\end{array}$ & $602 . . \cdot$ & $\begin{array}{l}\text { Septum transparent and perforated; } \\
\text { arachnoid thick and opague }\end{array}$ \\
\hline $\begin{array}{l}46 . \\
47 .\end{array}$ & F. & $\begin{array}{r}6 \\
60\end{array}$ & $\begin{array}{l}\text { Phthisis pulmo. } \\
\text { Carditis } \bullet . .\end{array}$ & Large quantity. & $\mid \begin{array}{l}\text { Very great } \\
\cdot \bullet \cdot \bullet\end{array}$ & $\begin{array}{l}\text { Cranium deep blue. } \\
\text { In the cut surface, holes like new } \\
\text { bread. Excavation in corpus callo- }\end{array}$ \\
\hline 48. & F. & 57 & $\begin{array}{c}\text { Carcinoma } \\
\text { breast, \&c. }\end{array}$ & Much fluid & Much fluid & $\begin{array}{l}\text { Skull softened and a layer of bone on } \\
\text { arachnoid. Blood vessels much } \\
\text { loaded. }\end{array}$ \\
\hline 49. & M. & 32 & $\begin{array}{l}\text { Diseased heart, } \\
\text { axillary aneu- } \\
\text { rism. }\end{array}$ & $\cdot \cdot \cdot \cdot$ & Much fluid & $\begin{array}{l}\text { Infiltration of substance. Mem- } \\
\text { branes opaque. }\end{array}$ \\
\hline 50. & M. & 44 & $\begin{array}{l}\text { Phthisis pul- } \\
\text { monalis. }\end{array}$ & Effusion & $\cdot \cdot$ & $\begin{array}{l}\text { Opacity of velum interpositum. } \\
\text { vascular spot on the pons varolii. }\end{array}$ \\
\hline
\end{tabular}

In this Table, effusion of serous fluid into the cavity of the arachnoid, or the sub-arachnoid tissue, or both, was observed in considerable quantity in nearly all the cases : in many of them several ounces were found in the ventricles.

A loaded or a diseased state of the blood-vesselsopacity and thickening of the membranes-with other morbid states, were noticed in many of the cases. 
The respective ages of the subjects were as follows :-

\section{TABLE II.}

Under 10 years . . in 4 cases.

Between 10 years and 20 years, 2

$\begin{array}{rrrrrrr}20 & . & . & \mathbf{3 0} & . & . & \mathbf{8} \\ \mathbf{3 0} . & . & \mathbf{4 0} & . & . & \mathbf{4} \\ \mathbf{4 0} & . & . & \mathbf{5 0} & . & . & \mathbf{5} \\ \mathbf{5 0} & . & . & \mathbf{6 0} & . & . & \mathbf{1 2} \\ \mathbf{6 0} & . & . & \mathbf{7 0} & . & . & \mathbf{1 0}\end{array}$

Upwards of 70 . $\quad . \quad$. $\quad . \quad 5$

It appears that between the ages of 50 and 70 nearly one half of the cases occurred.

\section{TABLE III.}

Of the diseases which occasioned death, there were of-

Phthisis pulmonalis . . . 16 cases.

Disease of the heart . . . 8

Purpura hæmorrhagica . . 1

Cholera . . . . . 1

Carcinoma and fungoid disease of $\mathbf{9}$ stomach, liver, kidney, \&c. . $\quad 3$

Pneumonia . . . $\quad$. 3

Peritonitis . . . . . 2

Phlebitis . . . . . 1

Crural phlebitis : . . . 1

Inflammation of liver and peritoneum 1

Mortification . . . $\quad$. 1 


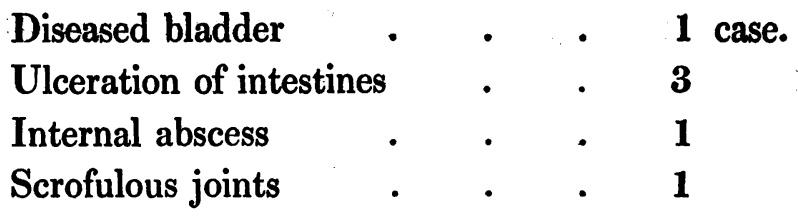

The proportion of cases of pulmonary tubercles, amounting to sixteen, is not greater than the ordinary comparative mortality from this disease; the cases of death from disease of the heart amount to eight.

When effusion of serous fluid has been noticed in the brain of persons dying of diseases of the thorax, it has generally been explained to arise from the obstruction to the free return of blood from the head in such patients. This explanation may apply to diseases of the heart in some instances, but it is very far from being capable of universal application. Besides, any one accustomed to pathological investigations must have observed how very frequently (more especially in the latter periods of life) disease exists in the muscular structure of the heart, and in the mitral and tricuspid valves, without having produced any notable inconvenience, and very frequently without having been discovered during life: it would therefore appear that human life is not shortened, in many instances, by very extensively diseased states of the heart. The explanation which has often been given respecting fluids found in the brain of phthisical subjects, viz., that it is part of the general wasting of the solids in this disorder, is more satisfactory than that of impeded 
return of blood from the head. The analogy holds with other diseases attended with extreme emaciation, as carcinoma ventriculi, of which there are three cases in the preceding Table.

\section{II.}

"Serous effusion into the ventricles or membranes to a considerable extent, in cases where old apoplectic cysts were found, with or without attendant paralysis, the patients being destroyed by diseases not cerebral."

\section{CASE I.}

Copious Effusion into the Ventricles; an Apoplectic Cavity in the right hemisphere filled with Serum. Death from Disease of the lungs.

Feb. 21, 1833. Ann Sheppard, æt. 48. She has had hemiplegia of the left side three years. She was admitted a month ago with aggravation of habitual cough and anasarca of the legs, resulting from diseased heart and lungs. She is an old gindrinker. Died from increase of pulmonary disease.

Inspection 41 hours after death.-Head. On removing the calvaria, the dura mater fell in upon the right hemisphere, and a large quantity of fluid escaped from an opening made by the saw; more than half of the substance of the right hemisphere was found to be wanting, and its place occupied by fluid covered by membrane; the brain forming the 
walls of the cavity was fawn coloured, and soft like jelly. The blood-vessels traversing the membranes in this direction were much enlarged and tortuous. But little cerebral substance was interposed between the ventricle and the apoplectic cavity. Nearly the whole of the septum lucidum was of a transparent fawn colour. Right ventricle very large; the part of its lining membrane adjacent to the cyst, thick and gelatinous. The pia mater and arachnoid forming the walls of the pouch were much thickened and opaque. Both the corpora striata stained as from imbibition. The substance of the left hemisphere and the cerebellum were healthy.

Thorax, heart.-Both auricles dilated. Right auriculo-ventricular opening dilated. Cartilaginous deposit on the tricuspid valve. Left auriculo-ventricular valve contracted; deposit of bone around the mitral valve.

Lungs infiltrated with sero-purulent fluid, and hepatized to a very great extent.

Abdomen.-The liver presented the fatty degeneration. A large fibrous tumour was found in the substance of the uterus.

Remarks. - In this case of old apoplexy, a large quantity of fluid was found in the ventricles, more especially in the right, which had most probably been gradually accumulating, and without any marked 
variation of symptoms. It is also remarkable for shewing the atrophy of one hemisphere of the brain subsequent to the attack of apoplexy, and the consequent supply of the place of the brain by serous effusion.

\section{CASE II.}

Extensive Effusion into the Membranes; a small Tumour in the right Corpus Striatum; a cavity in the right Thalamus. Death occasioned by Intestinal Disorder.

Ann Parr, æt. 78, has been in the paralytic ward 12 months. She has hemiplegia of the left side. Some time ago, she suffered an attack of diarrhœa, attended with dysenteric symptoms.

Inspection 34 hours after death. Dec. 18, 1833.-Head. Slight opacity of the membranes. A very large quantity of fluid was effused into the sub-arachnoid tissue: about half an ounce was contained between two of the convolutions on the posterior lobe of the left hemisphere. In the centre of the right corpus striatum was found a small hard body of the size of a pea, of irregular shape. A small cavity in the right thalamus. Both the thalami were diminished in size.

Thorax, heart.-Mitral and aortic valves thickened; aorta dilated. 
Lungs speckled with opaque semi-cartilaginous deposits on the pleura.

Abdomen.-An appearance of healed ulcers in several parts of the large intestines.

Remarks.-This patient sank exhausted from the disease of the intestines, without any increase of head-symptoms. It is an instance of very copious effusion of serous fluid into the sub-arachnoid tissue, connected with an apoplectic cavity in the right thalamus, and absorption of both these bodies.

\section{CASE III.}

An old Apoplectic Cyst with dilated Ventricles and copions Effusion of Serous Fluid. Death occasioned by Sloughs on the back.

Sarah Collins, æt. 67 years. Was bed-ridden for a great length of time, and died from exhaustion occasioned by sloughs on the sacrum.

Inspection 42 hours after death. Dec. 10th, 1834.-Head. The membranes were very much thickened, with a large quantity of fluid beneath the arachnoid. The lateral ventricles were dilated so as to contain $4 \mathrm{oz}$. each. The septum lucidum was very thin, but entire. The brain, fibrous and loose, as if from interstitial absorption. There was an old $\therefore$ wn coloured cyst in the posterior lobe of the left emisphere. 
Thorax, heart.-The aorta and its valves, as well as the coronary arteries were ossified. Lungs hepatized.

Remarks. - In this case the quantity of fluid accumulated in the ventricles, amounting to eight ounces, together with that abundantly effused from the membranes, had in all probability been slowly collecting for a considerable time past : the septum lucidum, though very thin, was entire, which is an evidence of the gradual deposition of fluid within the ventricles. The fibrous and loose texture of the brain is connected with the pathological condition which has been termed œdema cerebri.

\section{CASE IV.}

Copious Effusion into the Membranes and Ventricles; an old Apoplectic Cyst. Red ramollissement of the gray matter.

Elizabeth Lay, æt. 67 years, was admitted in a dying state, comatose. Has been bed-ridden with left hemiplegia for many years.

Inspection 19 hours after death. . Jan. 24, 1835. - There was a large quantity of fluid in the membranes and in the ventricles. Ramollissement with interstitial effusion of blood, was observed on several spots of the gray matter on the posterior lobes of the cerebrum. There was an old cyst in 
the right corpus striatum, partly involving the thalamus of the same side.-This case differs from the three preceding in consequence of the existence of a small portion of recent red ramollissement of the gray matter of the posterior lobes of the cerebrum, and the coma as a symptom. It may be considered as somewhat out of place here, but I have introduced it as an instance of long existing effusion connected with an old apoplectic deposit, the ramollissement most probably having occurred a few days before death.

\section{III.}

"Serous effusion into the ventricles or membranes of unquestionably long standing, and old apoplectic cysts, with recent extravasation of blood, which speedily destroyed life."

\section{$C A S E V$.}

An old Apoplectic Cyst in the Right Corpus Striatum; smaller cavities in other parts of the Brain; Hemiplegia with signs of recent Arachnitis, and Extravasation into the cavity of the Arachnoid.

Sarah Carrol, æt. 54, has had hemiplegia of the left side from an attack which occurred 18 months ago. She has been delirious for the last two weeks, almost incessantly screaming, and continually repeating her words. Pulse small, but always sharp and thrilling. 
Inspection. Nov. 11th, 1833. Fifty hours after death. Head.-There was considerable effusion of serous fluid between the arachnoid and pia mater, but not so much as in many similar cases. The arachnoid had throughout a milky appearance. The remains of an old apoplectic extravasation lined with fawncoloured matter was found in the centre of the right corpus striatum; there were several smaller cavities in different parts of the brain, lined by membrane, and containing fluid. A small layer of recently coagulated blood was found in the cavity of the arachnoid, upon the outer and posterior surface of the right hemisphere.

Remarks.-It is most probable that the effusion into the membranes was of old standing, from the opaque state of the arachnoid, together with the other morbid appearances noticed; and that the layer of extravasated blood, with the recent arachnitis, was the cause of death. The numerous small cavities in the brain I shall, in a succeeding paper, endeavour to point out as an evidence of white ramollissement having existed at some former period.

\section{$C A S E \quad V I$.}

Ancient Serous Effision into the Membranes and Ventricles; recent Extravasation into the Ventricles. Death in 80 hours.

Ann Baggs, æt. 71. She was suddenly attacked 
with apoplexy on the evening of Nov. 22, attended with paralysis of the left side. She lived eighty hours after the seizure, but the whole of the time was, apparently, in a moribund state.

Inspection 32 hours after death. Nov. 27th, On raising the skull-cup, the dura mater appeared turgid and tense. There was considerable effusion of serum between the membranes, with slight opacity ; two convolutions posteriorly were separated from each other half an inch, by the presence of a large quantity of fluid. On separating the hemispheres, the corpus callosum was evidently raised by fluid beneath, so as to make its distance from the surface inconsiderable. The ventricles were very large, and had evidently contained for some time past from six to eight ounces of fluid. They were distended with bloody serum, which, when removed, left a coagulum of blood lying loosely on the floor of both lateral ventricles. A rupture of a blood-vessel had taken place in the right thalamus, which was completely broken up and mixed with coagula; from this rupture the blood had passed through the septum lucidum, which had completely given way into the left ventricle, and also to the fourth ventricle, and to the surface of the cerebellum.

Thorax and abdomen not examined.

Remarks.-From the long continued dilated state of the ventricles, and the serous fluid in them as well 
as between the membranes, this case might have been considered a decided one of serous apoplexy, provided the patient had died rather suddenly, and no other morbid appearance had been detected in the brain or in any other organ. Whereas the case not only shews that life may go on without much inconvenience with the presence of a large quantity of fluid in the brain, but it also shews that the ventricles, being thus habituated to distension by fluid, were rendered less susceptible of the presence of extravasated blood in them, and consequently life was protracted longer than it otherwise would have been; for whenever blood is extravasated into the ventricles, death takes place, if not instantly, at least very speedily, and probably next in point of rapidity to extravasation into the tuber annulare.

\section{CASE VII.}

Fluid in the Membranes and Ventricles; an old Cyst; Holes in the right thalamus; and a recent Clot in the left thatamus.

William Tuttill, æt. 80. He had an apoplectic attack about eighteen months ago, attended with hemiplegia of the left side, from which he appeared to have recovered. He was admitted into the workhouse in nearly a dying condition, with muttering delirium, impeded articulation, and paralysis of one side of the face. He died a few days after admission. 
Inspection 38 hours after death. Head.-Thère was considerable opacity of the arachnoid, not uniform, but in spots. A large quantity of fluid was found between the membranes, and the blood-vessels were highly congested. The ventricles contained a large quantity of fluid; the right was larger than the left, and the floor of it softened. An old cyst, the size of a marble; with dark brown parietes, was observed in the substance of the right corpus striatum, and one or two very small colourless cavities in the thalamus of the same side. In the centre of the left thalamus there was a small clot of recently extravasated blood, the size of a pea, and of very dark colour; the fibres-of the pons varolii and medulla oblongata were very strongly marked. Many vesicles were noticed on the plexus choroides.

Thorax.-Tubercles were found in the lungs. The heart large, its cavities dilated. Ossification of the aortic and mitral valves.

Abdomen.-Liver dark coloured, loaded with blood. Stomach very much contracted.

Remarks.-In this case death was occasioned by the small extravasation of blood in the left thalamus, and probably the symptoms during his last illness were partly referable to arachnitis, and to this cause may also be attributed some portion of the fluid effused. It is also worthy of notice, in consequence of the disappearance of the left hemiplegia and its 
connection with the traces of arrested ramollissement in the right thalamus.

\section{CASE VIII.}

Old serous Effusion between the Membranes and in the Ventricles. Death from copious Extravasation, which was prevented from entering the ventricle by its tough lining membrane.

Mary Cornwall, æt. 60. Has been a cook, she is a very large woman. Whilst standing at the wash-tub she was suddenly seized with an apoplectic fit, Jan 7th. She was partially sensible, with left hemiplegia. On her admission on the 8th; she was in a nearly hopeless condition; she however rallied a little on the 10th, and died on the 12th. Pupils were firmly contracted from the time of her admission.

Inspection 55 hours after death.-Head. Spots of extravasated blood were observed beneath the arachnoid coat : considerable opacity and effusion between the membranes: ventricles dilated. A large clot of blood was found in the substance of the right thalamus, which was prevented from entering the ventricle by a membrane which was seen beautifully distended, and which, from its toughness, prevented the entrance of the blood from the thalamus into the ventricle. The blood had made its way down by the side of the crus cerebri, and extended beneath the 
opposite thalamus. On making a section into the substance of the brain above the clot in the thalamus, interstitial extravasation of blood had taken place.

Thorax.-Heart large, mitral valve rough.

Remarks.-Among the signs which distinguish ancient from recent effusion into the ventricles, I believe the entire and extended state of the septum lucidum, and the thickened state of the lining membranes of the rentricles, may be considered as strikingly marking the first; and a torn state of the septum, and softening of the central cerebral matter, with a natural or a thin state of the lining membrane, as denoting the latter. In this case, the lining membrane was so tough as to admit of distension, and to prevent the entrance of blood into the ventricle, the course the blood would in all probability have taken, in preference to passing along the crus cerebri and insinuating itself beneath the opposite thalamus.

\section{CASE IX.}

Effusion into the Ventricles and beneath the Membranes: old Apoplexy; recent interstitial Extravasation with ramollissement.

Henry Stock, æ. 70. Admitted March 28th, with stertorous breathing: he appeared nearly insensible, but still could answer questions when roused. 
He had some time ago an attack of apoplexy, to which succeeded hemiplegia of the left side. His pulse was large and full, but was very soon influenced by depletion. He died about three days after admission.

Inspection. April 1st. Brain.-The membranes were distended with an unusual quantity of opaque serum, in some parts in the form of small bladders. The ventricles contained much fluid. On the surface of the right hemisphere were several fawn-coloured spots: towards the centre, and contiguous to an old cyst in the right corpus striatum, the cerebral substance was softened. The corpus striatum had almost disappeared by absorption, its place being occupied by filamentous tissue and fawn-coloured fluid. The lining membrane of the ventricle was seen stretched across this old cyst. There was ramollissement of the left corpus striatum, with interstitial extravasation of blood, which was probably the cause of the fatal attack.

Remarls. - In this case the brain appears to have sustained very great injury at the time of the first apoplectic attack: there was probably a large clot, attended with ramollissement of the surrounding parts of the brain. The wasted state of the right corpus striatum, with the fawn-coloured spots on its surface, are evidence of this softening having been arrested or cured. There appears to have been 
a tendency in this man's brain towards the state of ramollissement, for the fatal extravasation took place into a softened part of the left corpus striatum.

\section{CASE X.}

A Maniac with Amaurosis : extensive Effusion beneath the Membranes and into the Ventricles; Death from Extravasation of blood into the cavity of the Arachnoid.

Thomas Dalton, æt. 50, six feet high, has amaurosis of both eyes, which is reported to be consequent on purulent ophthalmia. He was admitted into the insane ward about three weeks ago. During the first part of the time he was quiet, but latterly he was occasionally boisterous and required restraint. Early in the morning of the 7th instant, one of the medical assistants was called up to him, who found that he had suffered an apoplectic seizure. Signs of approaching dissolution soon came on, he however rallied a little, and lived about thirty hours after the attack.

Inspection 25 hours after death. Nov. 9th, 1833. Brain.-A large quantity of fluid was discovered between the membranes, and also in the ventricles. Nearly the whole of the arachnoid lining the dura mater on the left side was covered with a layer of coagulated blood, and in a slight degree also on the right side : the layer was thicker at the posterior part 
of both hemispheres. One of the large veins of the pia mater was distinctly observed to have been ruptured. 'The vessels of the pia mater and the substance of the brain were unusually loaded with blood. The substance of the brain, particularly the gray matter, was remarkably hard, resembling soft cartilage to the knife. The optic nerves throughout their course appeared like flattened cords of filamentous tissue, without any of the ordinary substance of a nerve. The corpora quadrigemina were remarkably diminished in size.

Thorax.-Heart; globular hypertrophy of the left ventricle, but to a very small extent.

Remarks.-The history of this patient, together with the appearances presented on dissecting the brain, shew that the fluid between the membranes and in the ventricles had long existed. The hardened state of the cerebrum has occasionally been noticed in the brains of maniacs. The patient lived longer than is usual with extensive extravasation on the surface: this may probably be accounted for by the arachnoid and surface of the brain being long accustomed to the morbid presence of serous fluid, that they were consequently rendered less impatient of the blood extravasated from the rupture of the pia matral vein. The dwindled state of the optic nerves has been usually observed in cases where the eye-ball has long been useless. 


\section{IV.}

Simple Sanguineous Apoplexy.

The following examples of simple sanguineous apoplexy, tend to illustrate the anatomy of those cases which have been denominated serous apoplexy.

Although the terms congestion, vascular fulness, loaded state of the blood-vessels, hyperemia, are so frequently and familiarly applied to denote a pathological condition of the brain, yet some authors have denied the possibility of this circumstance occurring within the cranium, because they are unable satisfactorily to account for such a state of the brain. It is sufficient for my purpose, to allude to some of the phenomeha on which the affirmative of this question is grounded, without entering on its discussion*. We frequently observe the skull to be nearly white, at other times it presents a mottled or deep purple colour, and this occurs in persons of all ages. Compared with the ordinary fulness of the brain, we frequently observe a general bright red colour of more or less intensity, and in some of the sections made by the knife it has a beautifully mottled appearance, resembling a minute injection of the capillary arteries

* See two papers by Dr. Kelly in the 1st vol. of the Edinburgh Medical and Chirurgical Transactions, Dr. Abercrombie's work, and others. An Experimental Investigation of the Effects of Loss of Blood. By Dr. Marshall Hall. Med. Chir. Trans. Vol. XVII. 
and veins. The veins of the pia mater and plexus choroides, and the whole substance of the brain, are often seen gorged with deep purple blood, of which the brain of a cholera patient is a striking instance. In a brain not loaded with blood, the vessels on the surface and in the central parts are in some cases remarkably dilated, and also when there appears no disease of the coats of the vessels. An objection is generally urged, that from the appearance of paleness or congestion in the dead brain, where the circulation is finally stopped either slowly or suddenly, we cannot infer that similar phenomena occurred in the living brain, when the circulation existed. If this argument be carried out, it will equally apply to the vascular system in every other tissue or organ of the body. It has often been remarked, that the appearance of cerebral congestion is influenced by the thorax being first opened, and the great vessels of the neck being divided, or otherwise : I have often made observations on this point and not found it so ; indeed, for obvious reasons, it is impossible in the majority of cases.

It is highly probable, that a form of simple sanguineous apoplexy frequently takes place in the convulsions of children. The brain of infants presents a more uniformly deep red tinge throughout than the brain of those more advanced in life. The texture of the brain at this age is so tender, that it allows of a more free dilatation of the numerous blood-vessels ramifying 
in it, and the consequent congestion of blood in them, when exerted by any unusual impression or irritation; and hence may arise the greater frequency of convulsions or simple sanguineous apoplexy in infants, compared with analogous affections in adults.

\section{$C A S E X I$.}

Convulsions in a Child; Death in the first fit ; high Congestion in the brain.

I was asked to visit the child of a person in my neighbourhood, said to be suffering a severe convulsion fit of longer than usual duration. The child had just died on my arrival. It was eleven months old, and was under treatment for some ailment connected with its teeth. This was the only fit the child had suffered.

Inspection.-On examining the head, the dura mater was found highly red. The vessels of the pia mater and those distributed in the substance of the brain were gorged with blood. The plexus choroides was highly vascular and of a livid colour. Some of the veins entering the longitudinal sinus were loaded with blood.

The next case occurred in an older child, and in this instance, the apoplectic state was more completely shewn by the symptoms. 


\section{CASE XII.}

Convulsion; simple Sanguineous Apoplexy in a child; extreme Injection of the Blood-vessels.

John Jones, æt. 6 years, became dull and stupid, and could not raise himself in bed; he appeared to: have lost all power over the muscles of his extremities. Pupils dilated. He had an attack of convulsions on the 7 th of March, and a complete apoplectic seizure the evening before his death.

Inspection, March 12, 1834, 17 hours after death. Brain.-The blood-vessels, membranes, and substance of the brain exhibited extreme congestion throughout. The blood-vessels of the pia mater were beautifully and finely injected. The substance of the brain and medulla oblongata was very firm. Weight 2 lb. 11 oz.

Thorax.-Lungs; hepatization of inferior part of left lung to some extent and of long standing.

'Abdomen.-Stomach distended; mucous membrane soft, mesenteric glands enlarged.

Remarks.-In the first of the two preceding cases, the loaded state of the blood-vessels of the brain existed in a very remarkable degree. The brain of an infant dying in comparatively good condition, is generally in a state of congestion, but the appear- 
ance is very different from that which $I$ have just related. In the second case, No. XII., the symptoms and appearances on dissection exactly corresponded with sanguineous apoplexy in an adult.

A few days ago I was called to see the following case, which appears strikingly to illustrate this view of the pathology of convulsive disease in children.

\section{CASE XIII.}

Long continued Convulsion; Paralysis ; recovery.

Aug. 11th. A child, aged 2 years, was suddenly seized with strong convulsion, about two p.m., in which she continued for nearly one hour and a half. No teeth were pressing, the gums had been freely lanced several times. The weather was very hot, which, with disordered stomach in a rather delicate child, might produce the fit. In about half an hour from the commencement the spasms abated, and it appeared going off: agitation of the left extremities was again observed to increase, and the symptoms returned in all their violence. Local bleeding, warm bath, cold to the head, purgatives, injections were assiduously persevered in, which happily succeeded. The convulsion ceased and the child fell asleep. Nine, p.m. Has slept several hours; is sensible; she does not move the left lower extremity, nor flinch on its being pinched; there is rigid contraction of the left arm. Leeches to the right side of the head; blister 
to the back of the neck; calomel. 12th. Slept well ; sensibility and power over the left side restored; no other symptoms appear. 13th. Recovered.

\section{CASE XIV.}

Simple Sanguineous Apoplexy; extreme Congestion in the brain and in the lungs.

A. B., æt. 23 years, a stout muscular young man, six feet two inches high, very short neck, accustomed to high living, whilst reading was suddenly seized with apoplexy. He screamed out immediately on the attack and sunk into a state of insensibility, from which he was never roused. He died in the course of a few hours.

Inspection. - Head. Scalp highly congested. Skull purple, mottled with blood. Brain: the dura mater adhered to the bone, and the superior part came off with the calvaria. There was slight serous effusion in the sub-arachnoid tissue over a few of the intergyral spaces. The blood-vessels throughout the membranes and the substance of the brain were gorged with blood; a large quantity of blood flowed from the incisions made into the sinuses. No extravasation could be detected. There was a small quantity of fluid in the ventricles, and the central parts of the brain were rather soft.

Thorax.-Heart rather large, but natural in struc- 
ture. The lungs were loaded with blood posteriorly. A large quantity of fluid blood was found in the trachea and ramifications of the bronchi. No laceration of the texture of the lungs or of any bloodvessel could be detected. The capacity of the thorax appeared to be encroached upon by the liver.

Abdomen.-Stomach contracted and rugous, the mucous membrane vascular. The liver was more than twice the natural size, in part from congestion, without any apparent change of texture.

Remarks.-This case presents a striking example of simple sanguineous apoplexy of the most severe character. No extravasation could be traced on the most minute examination of the brain. The congestion in the lungs was extreme, and it is highly probable that some part of the blood found in the air passages had transuded from the air-cells or the more delicate ramifications of the bronchi.

\section{CASE XV.}

Simple Sanguineous Apoplexy; Paralysis of the face; loaded state of blood-vessels; slight Serous Effusion.

Rachel Batts, æt. 60 years, went to bed as well as usual, and on Feb. 1st, after sleeping several hours, she awoke in a stupid state. When brought into the infirmary, the pupils were contracted almost to a 
pin-point aperture. She was partly conscious, and put out her tongue, when asked to do so, which was drawn to the left side. The right side of the face was paralysed, and the left corner of the mouth drawn down. She lived about three days.

Inspection 14 hours after death.-Head. The cranium was largely developed in the superior and lateral portions. Deep cribriform pits along the tract of the great meningeal artery on the parietal bones. Brain : the blood-vessels were throughout highlyloaded with blood, but without any extravasation. There was some serous effusion between the membranes and in the ventricles, but in very small quantity. The brain was firm, and weighed $3 \mathrm{lb} .2 \mathrm{oz}$.

Remarks.-This is evidently a case of simple sanguineous apoplexy, occasioned by the loaded state of the blood-vessels of the brain. The quantity of serous fluid found between the membranes and in the ven-' tricles will not account for the death of the patient on the principle of serous apoplexy. The brain was heavy; and it not unfrequently happens that the weight of the brain is increased in proportion to the quantity of blood which the distended vessels appear to contain. In a man, æt. 35 years, who died from extensive pleuro-peripneumonia, attended with delirium before death, the brain was found highly loaded with blood, and weighed 3 lb. 6 oz. Numerous instances illustrative of this point will be found in a succeeding paper on hypertrophy of the brain. 


\section{CASE XVI.}

Simple Sanguineous Apoplexy; excessive venous Congestion in the Brain; dilated left Ventricle of the heart and diseased Mitral Valve.

Isabel Harding, æt. 45 years, a person of weak intellect, but of a strong and robust habit of body. Having made no complaint during the day, she was suddenly seized with apoplexy after supper in the evening. She had strong convulsions, her head was drawn firmly to the left side, and both the left extremities were in a state of rigid spasm; foaming at the mouth; laborious breathing. She was perfectly insensible. Pulse large and full. She was bled copiously from the arm and temporal artery, was cupped, blistered, and took calomel. Her pulse fell on the 18th, with a partial return of consciousness. On the 19th she was much worse; extreme debility with coma. She died on the $22 \mathrm{~d}$.

Inspection 36 hours after death.-Brain. Old opacity of the membranes was observed with the usual effusion beneath. There was very great venous congestion throughout, and in all other respects the brain was healthy, without any trace of lesion or extravasation. The brain was moderately firm, and weighed 3 lbs.

Thorax.-Heart: left ventricle much dilated, the mitral valve rugged, with thickened chordæ tendineæ. 
Portions of the lungs hepatized of some duration. Bronchial membrane injected and thickened.

Abdomen.-Mucous membrane of stomach softened and lacerable; liver soft; congestion in the portal system.

Remark.-This case is an instance of sudden apoplectic seizure attended with insensibility and spastic contraction of one half of the body, and on dissection we find the brain excessively loaded with blood.

In the preceding part of this paper, numerous facts have been produced to shew that serous fluid exists in very many instances in the brain of persons who died of diseases not cerebral, and who manifested no symptoms of effusion; that fluid is often effused in great quantity in the membranes and ventricles of those persons who have previously suffered apoplexy with extravasation of blood; and that some of these persons live to the ordinary period of human life, being carried off by various disorders, and that others are destroyed by subsequent extravasation of blood in the brain. I then detailed several striking instances of simple sanguineous apoplexy occurring in persons of various ages. Having taken these preliminary steps, which form the ground work of the argument, we shall be better able to appreciate those cases related in the next section, which have been termed serous apoplexy, and to appro- 
priate them to their proper place in the class of diseases of the nervous system.

\section{V.}

"Cases of serous effusion into the ventricles or membranes of old standing, with loaded, dilated, or diseased blood-vessels, frequently termed serous apoplexy, but more probably referable to simple sanguineous apoplexy."

\section{CASE XVII.}

Copious effusions of Serous Fluid into the Ventricles; dilated Blood-vessels; small cavities filled with Serum in the Thalami.

William Miller, æt. 55. Paralytic and half-idiotic for many years. On Feb. 24th, in the evening, he suddenly cried out and was seized with strong convulsions resembling epilepsy. The left side was paralysed; the right side of the face and right extremities were strongly convulsed. His pupils were dilated and insensible to light. The eyes drawn towards the right side. Insensible to pinching. Pulse full and bounding. He was bled twice and cupped, but his symptoms continued to increase; he had occasional convulsions, became comatose, and died two days after the attack.

Inspection 14 hours after death.-Head. On removing the dura mater the surface below was strik- 
ingly marked by the fibrous lines of the dura mater. The contiguous portions of the arachnoid of the two hemispheres of the cerebrum adhered intimately where they touch below the falx. The blood-vessels of the brain were large and dilated. The convolutions flattened. The substance of the brain was remarkably tough, particularly near the ventricles. All the ventricles were dilated, and might contain about eight ounces of fluid. The corpora striata were atrophied, and contained numerous small cavities filled with serum. Weight 2 lbs. 13 oz.

Heart.-Hypertrophy of left ventricle, both auricles dilated. Diseased valves. Old pleuritic adhesions.

Kidneys * granular; a cyst on one the size of a walnut.

Remarks.-The unusual firmness of the substance of the brain, particularly near the ventricles, renders it probable that the fluid had been effused into the ventricles a long time back : from this appearance, and from the atrophy of the corpora striata, and the vesicles contained in these bodies, together with the history of the case, I suppose the patient had been the subject of ramollissement of the central part of the brain at some former period of his life. The character of the fatal attack, and the flattened appearance

* See notice of a paper "On Fits and Sudden Death, in connection with Diseases of the Kidneys, by James A. Wilson, M.D." Medical Gazette, Vol. XI., p. 777.

voL. XIX. 
of the convolutions, indicate pressure from some cause or other; and I think, taking all the circumstances into consideration, it is quite as probable that it was occasioned by congestion in the dilated blood-vessels, as to suppose that it arose from the serous fluid in the ventricles, which I before stated had, in all probability, existed for a great length of time.

\section{CASE XVIII.}

Copious Effusion into the Ventricles; great Congestion of Blood-vessels; old Cysts ; Atrophy of the Brain.

William Parker, æt. 62. He suffered an apoplectic fit late in the evening of Aug. 4th, 1834. His face was drawn to the left side; there was paralysis of the right arm and leg. His intellect had become im. paired, and he had been confined to bed three or four months past. He has dragged his right leg for twenty years. He lived about 24 hours after the attack.

Inspection, Aug. 6th, ten hours after death.Head: Brain. Dura mater was tough and there were opaque spots on the arachnoid. The blood-vessels were very considerably loaded. There were two cysts of old standing on the superior surface of the right hemisphere, as large as a walnut; the lining was fawn-coloured, and they contained fluid : these cysts did not touch upon the central parts of the hemisphere. A similar cyst existed in the centre of 
the left hemisphere; the corpora striata and thalami were entire, and appeared healthy. On the surface of the right lobe of the cerebellum there were small remains of an old extravasation. The ventricles were very large, and contained several ounces of fluid. The brain appeared much diminished : weight $2 \mathrm{lbs}$. $60 z$.

Remarks.-In this case it is most probable that death was occasioned by the loaded state of the bloodvessels, constituting an example of simple sanguineous apoplexy. The atrophy of the brain, together with the traces of old apoplectic deposits in several parts, denotes that the serous fluid had existed for a long time, and had probably no share in producing the fatal event.

\section{CASE XIX.}

Copious Effusion into the sub-arachnoid Tissue, and into the Ventricles; Congestion of the Brain; Hypertrophy of the Cranium. Sudden death.

Susan Fleming, æt. 89. About two months ago she suffered an apoplectic attack, which left hemiplegia of the right side and imbecility of mind. She died suddenly, after raising herself in bed.

Inspection, fifty-nine hours after death, Dec. 3, 1834. Head : hypertrophy of cranium on the interior of the frontal region. The dura mater adhered 
firmly to the cranium. The arachnoid was opaque and thick, and raised by a large quantity of fluid effused beneath it. The ventricles were distended with fluid, and the septum lucidum was reduced to a pulpy mass. A large quantity of blood escaped on opening the skull, and the smaller blood-vessels of the brain were much injected. No lesion or extravasation could be detected. Weight 2 lbs. 12 oz.

Remarks. - In this case the serous fluid had been accumulating for a considerable length of time. The large quantity of blood that escaped from the lateral sinuses on making the section of the skull, and the injected state of the smaller blood-vessels, are a sufficient cause to account for the sudden death. The pulpy state of the septum lucidum, examined fiftynine hours after death, and in so old a subject, can scarcely, I imagine, be considered as influencing the fatal event.

\section{CASE XX.}

Apoplexy; Arachnitis; Effusion of Serum beneath the Membranes and into the Ventricles; great Congestion of the Blood-vessels.

John Gough, æt. 40. He dropped down suddenly in a fit, whilst grooming a horse, July 29th, 1834 . He remained insensible all the night, and when admitted in the morning he appeared in a state of stupor, as if from intoxication; his head dropped on 
his chest, and he was throwing his arms and legs about. Pulse very small. He rallied sufficiently in the evening so as to relate some of the occurrences preceding the fit. Convulsive twitchings of left extremities, afterwards of both sides, came on: delirium, loud talking, and great heat of the scalp. No palsy. He died eight days after the fit.

Inspection, Aug. 6th, eight hours after death. Head: skull thick. The membranes were very opaque, tough, and contained a considerable quantity of fluid. The blood-vessels of the membranes and brain were loaded with blood, but no extravasation or lesion could be detected. The ventricles were large, and contained several ounces of fluid. The brain was tough and stringy, and weighed 2 lbs. 14 oz.

Thorax : heart large, ossification of aorta, and thickened mitral valves. Right lung emphysematous.

Abdomen: one or two cysts on the kidneys; and the external surface was irregular and slightly granular.

Remarks.-From the state of the membranes, and the tough and fibrous state of the brain, there can be no doubt that a great quantity of serous fluid was present in the cranium at the time of the apoplectic attack. I apprehend the sudden fit to have been one of simple sanguineous apoplexy, occasioned by vascular fulness: the subsequent arachnitis might increase the effusion in the sub-arachnoid tissue. 


$$
\text { - CASE XXI. }
$$

Very copious Effusion into the Ventricles; an old Cyst; Congestion of the Brain.

Ann Thacker, æt. 71. Admitted Jan. 14, 1833, in a very feeble state. In February she lost the left eye from inflammation and suppuration of the internal textures: calomel was given her as a remedy, which produced copious salivation. She recovered, and continued tolerably well up to March 14th, when stupor and drowsiness came on. The remedies applied produced no effect in rousing her : her pulse gradually fell, the coma became nearly complete, and she died on the 16th.

Inspection, March 17th, twenty-eight hours after death. Brain: the blood-vessels of the membranes and substance of the brain were turgid with blood. A large quantity of fluid was found in the sub-arachnoid tissue. The ventricles were largely dilated, and capable of containing $12 \mathrm{oz}$. of fluid. The septum lucidum transparent and cribriform. In the posterior part of the left thalamus there were the remains of an old cyst, about the size of a sixpence, the surface of which was covered with an ochry deposit.

Thorax. Heart : ossific deposit on the aorta, and at the base of the aortic valves. Lungs: old pleuritic adhesions.

Abdomen: hyperemia of the mucous membrane of the great intestine. 
Remarks.-This case is remarkable for the extent of serous effusion into the ventricles, amounting to $12 \mathrm{oz}$. : from the general appearance of the brain, and the state of the septum lucidum, there is every reason to believe that the fluid had existed there for a considerable time, and that it had been slowly accumulating. The supervention of stupor and her speedy death, are more likely to have arisen from the congestion of the blood-vessels than from any pressure exerted by a sudden or rapid increase of the fluid.

As this and the succeeding papers are strictly pathological, $I$ have in many of the cases given but a short account of the chief or prominent symptoms, and I have also said little or nothing respecting the medical treatment.

There is no class of diseases in which the histories are liable to so many sources of fallacy as those of the brain, resulting as well from the state of our knowledge of the physiology and pathology of this organ; as from the imperfect and deceptive accounts we obtain from the subjects of these diseases.

The principal object I have had in view, in the course of this paper, has been, to shew that most of the cases of reputed serous apoplexy do not arise from the presence of the serous fluid within the head, but are referable to simple sanguineous apoplexy; yet I am not prepared to state that no such disease as serous apoplexy exists: on the contrary, there are 
some rare cases reported that do not appear to admit of explanation on any other ground.

It will be obvious that the foregoing facts and observations do not apply or refer to the acute form of inflammation of the brain termed hydrocephalus acutus of children or adults, in which a collection of fluid in the ventricles forms one of the pathological conditions observed on dissection.

We daily observe the pernicious consequences which result from a disposition to generalize on a few particulars in the science and practice of medicine, and I wish to avoid this error; but I submit that the foregoing facts, with many more that might be cited, render the following inferences highly probable :-

1st. That very copious effusion of serous fluid is found between the membranes and in the brain of persons of all ages, more especially between the ages of fifty and seventy years, who have died of various diseases of the thorax and abdomen, and who manifested no appreciable symptom of cerebral disease during life. That under similar circumstances, various other morbid appearances are found in the brain, as thickened membranes, diseased blood-vessels, tumours, \&c. That these several morbid states of the brain did not occasion the death of such persons.

2dly. That effusion of serious fluid into the ven- 
tricles and membranes, to a very considerable extent, exists in the brain of persons who have suffered previous apoplectic attacks, attended with paralysis and general or partial atrophy of the brain. That, most probably, this effusion and atrophy have existed for many years, without producing the disease termed serous.apoplexy : that persons so circumstanced live to an advanced age, and are destroyed by other maladies.

3dly. That in persons whose brain has long contained a large quantity of fluid, with or without any trace of previous apoplectic extravasation, and who have suffered a first attack or a subsequent attack of fatal apoplexy, it is probable that the brain, from this cause, is rendered less impatient of injury from extravasation of blood. This position is exemplified in a remarkable manner in Case VI., of extravasation into the ventricles, and in Case $X$., of extravasation on the surface of the brain.

4thly. That a loaded state of the blood-vessels is sufficient to produce all the symptoms of sanguineous apoplexy, and to occasion death without extravasation. It is probable that when this state of the vessels is found connected with only a small quantity of fluid in the membranes or ventricles, that death has been occasioned by simple sanguineous apoplexy. That convulsions in children, arise in general from cerebral congestion, and are essentially cases of sanguineous apoplexy. 
314 ON SEROUS EFFUSION IN THE BRAIN.

5thly. The conclusion is highly probable, that in very many instances of sudden or speedy death, which have been supposed to be occasioned by the presence of serous fluid discovered on dissection in the membranes or ventricles, death is not attributable to this fluid, or to serous apoplexy; but the inference is much more reasonable, that these cases may be referred to simple sanguineous apoplexy, the fluid in the brain having nothing to do with the fatal event. 